Anneliese A. Moss and the Barrister David T. Donaldson from London resolved this problem excellently through brief German and English commentaries which are added to the main legal terms. These commentaries are the very core of the dictionary. Both the English and American terms are given wherever they differ with their origin indicated. Side by side with the legal terms this volume contains an amazing number of general terms which make it also outside the field of law a very useful one. To sum up, this is an highly recommendable dictionary of legal, commercial and political terms.

Rainer Lagoni

\title{
Felix Becker
}

Die Hansestädte und Mexiko. Handelspolitik, Verträge und Handel, 1821-1867

Acta Humboldtiana, herausgegeben im Namen der Deutschen Ibero-Amerika-Stiftung durch Wolfgang Haberland, Nr. 9, Franz Steiner Verlag, Wiesbaden 1984, IX, 126 S., DM 38,-

Die Auslandsbeziehungen Hamburgs sind ebenso wie die anderer Bundesländer zahlreich, sie sind teilweise institutionalisiert. Kürzlich schloß die Hansestadt einen Vertrag mit der Hafenstadt Shanghai, in New York und Tokio arbeiten seit Jahren HamburgBüros, die Interessen der Hansestadt bei den Europäischen Gemeinschaften werden von einem Beauftragten wahrgenommen. Anfänge einer derart rührigen Vertretung der Interessen der Hamburger Wirtschaft könnte es - so vermutet man - bereits im vorigen Jahrhundert gegeben haben.

Die Vermutung ist irrig. Zwar trifft es zu, daß es auch damals darum ging, die Interessen der Wirtschaft der Hansestadt - und das hieß: die Handelsinteressen - im Ausland und insbesondere in Ubersee zu vertreten. Aber dies waren nicht Anfänge heutiger Bemühungen, diese sind allenfalls Rudimente damaliger Tätigkeiten. Damals wurden die Vertretungen auf konsularischer Ebene etabliert, die Mittel wirksamer Interessenvertretung waren Handels-, Schiffahrts- und Freundschaftsverträge; hierin waren die Hansestädte Vorreiter unter den Staaten des Deutschen Bundes.

Gegenstand der zu besprechenden Studie sind die Beziehungen zwischen den Hansestädten Hamburg, Lübeck und Bremen und Mexiko von der Unabhängigkeit Mexikos im Jahre 1821 bis zur Gründung des Norddeutschen Bundes im Jahre 1867. Der Verfasser gliedert seine Ausarbeitung in fünf Kapitel (Vom spanischen Handelsmonopol zur Freiheit des Handels - S. 1 bis 10 -, Staatliche Unabhängigkeit und Freiheit des Handels: vertragliche Absicherung - S. 11 bis 50 -, Vertrag und Wirklichkeit - S. 51 bis 80 -, Höhepunkt hanseatisch-mexikanischer Beziehungen - S. 81 bis 106 -, Rückblick und Bilanz - S. 107 bis 113 -). Er schildert nicht nur die Handelsbeziehungen vor der Unabhängigkeit Mexikos, die Interessenlage und die Verhandlungen zum Abschluß der Handels- 
verträge bis zu ihrer Ratifizierung, sondern geht auch auf die vertragliche und außervertragliche Praxis ausführlich ein, was einen besonderen Wert der Studie ausmacht.

Dabei wird deutlich, welche besonderen wirtschaftlichen Probleme ein rohstoffreiches, aber industriearmes Entwicklungsland ohne nennenswerte eigene Flotte damals belasteten und in welcher Weise die norddeutschen Handelsrepubliken in der Lage waren, durch ihre Handelsaktivitäten den Interessen Mexikos zu entsprechen. Es wird aber auch verständlich, welche Belastungen des Handels daraus erwuchs, daß die staatliche Infrastruktur schwach entwickelt und die staatliche Gestaltung zwischen den Mexikanern umstritten und umkämpft war. Dabei ist zu berücksichtigen, daß die Hansestädte zur Wahrung ihrer Interessen und Rechte nicht auf militärische Machtmittel zurückgreifen konnten wie etwa Großbritannien oder Frankreich, was ihnen indessen nicht nur Nachteile einbrachte: die Kaufleute machtloser Handelsrepubliken, denen keine "warlike naval states" zur Seite standen, wurden von den mexikanischen Politikern bevorzugt. Auch die Anknüpfung von Handelsbeziehungen zu dem neugegründeten Norddeutschen Bund erfolgte durch hanseatische Vermittlung.

Die besonderen Beziehungen zwischen Mexiko und den Hansestädten wird deutlich, wenn man erfährt, daß in den sechziger Jahren des vorigen Jahrhunderts deutsche Kaufleute - vornehmlich hanseatische - zwei Drittel des mexikanischen Außenhandels abwickelten. Die Freiheit des Handels sicherte die Unabhängigkeit Mexikos: dadurch, daß es sie gewährte, erhielt es Anerkennung. Insofern sind die untersuchten Handelsbeziehungen über die wirtschaftlichen Beziehungen hinaus bedeutsam.

Die lesenswerte und sehr lesbar geschriebene Studie von Felix Becker stützt sich nicht nur auf veröffentlichte Quellen und Literatur, sondern wertet auch unveröffentlichtes Quellenmaterial aus dem Staatsarchiv Hamburg und dem Staatsarchiv Bremen sowie aus dem Politischen Archiv des Auswärtigen Amtes in Bonn aus. Gegenüber dem Herausgeber wäre der Wunsch zu äußern, daß er die Beleuchtung hanseatisch-südamerikanischer Beziehungen im 19. Jahrhundert fortsetzt durch weitere ähnliche Untersuchungen, etwa der hanseatisch-brasialianischen (Handelsvertrag vom 15. November 1827), hanseatisch-venezuelanischen (Handelsvertrag vom 27. Mai 1837), hanseatisch-guatemaltekischen (Handelsvertrag vom 25. Juni 1847), hanseatisch-costaricanischen (Handelsvertrag vom 10. März 1848), hanseatisch-neugranadischen (Handelsvertrag vom 3. Juni 1854), hanseatisch-nikaraguanischen (Handelsvertrag vom 26. Juli 1855) und hanseatisch-dominikanischen (Handelsvertrag vom 12. Mai 1855).

Günter Hoog 